\title{
Flujos de inversión extranjera directa: un análisis de los casos de la Argentina, el Brasil, Chile y México basado en el índice Grubel-Lloyd
}

\author{
Álvaro Alves de Moura Junior, Pedro Raffy Vartanian \\ y Joaquim Carlos Racy
}

\section{Resumen}

En este artículo se evalúa la importancia del índice Grubel-Lloyd como herramienta para revelar las tendencias de la inversión extranjera directa (IED). El índice se desarrolló para avanzar en el estudio de una cuestión fundamental en la economía política internacional: cómo la IED afecta a las economías individuales o regionales, y se convierte en un indicador marco general del comportamiento regional. El índice se aplica a las cuatro mayores economías de América Latina (Argentina, Brasil, Chile y México) en el período 1995-2016, a fin de demostrar la importancia de la IED para la región. Sin embargo, el "comportamiento" de la IED puede ser diferente en cada país. Se analizan las características de cada uno de estos países que difieren de las encontradas con el mismo indicador en un bloque formado por los países desarrollados más China, para el que el índice calculado es más alto y varía poco durante el período analizado.

\section{Palabras clave}

Relaciones económicas internacionales, globalización, inversión extranjera directa, empresas trasnacionales, medición, Argentina, Brasil, Chile, México

\section{Clasificación JEL}

F20, F21, F23

\section{Autores}

Álvaro Alves de Moura Junior es Profesor e Investigador del Programa de Posgrado en Economía y Mercados de la Universidad Presbiteriana Mackenzie (Brasil). Correo electrónico: alvaro.moura@mackenzie.br.

Pedro Raffy Vartanian es Profesor, Coordinador e Investigador del Programa de Posgrado en Economía y Mercados de la Universidad Presbiteriana Mackenzie (Brasil). Correo electrónico: pedro.vartanian@mackenzie.br.

Joaquim Carlos Racy es Profesor e Investigador del Programa de Posgrado en Economía y Mercados de la Universidad Presbiteriana Mackenzie (Brasil). Correo electrónico: joaquimcarlos.racy@mackenzie.br. 


\section{Introducción}

Las finanzas se consideran el eslabón central en la actual etapa de globalización, así como el determinante clave de muchos acontecimientos en otras esferas del sistema económico internacional. La expansión de la liquidez internacional, especialmente desde la década de 1990, ha impulsado un aumento significativo de los flujos tanto de capital de cartera como de inversión extranjera directa (IED).

Según Corazza (2005), estos resultados, que reflejan la globalización financiera, son el resultado de tres factores interrelacionados: i) el alto nivel de acumulación de riqueza monetaria y financiera, como activos con diferentes grados de liquidez y negociados en numerosas monedas; ii) el desarrollo de recursos tecnológicos que hacen que estos activos sean extraordinariamente móviles, y iii) el actual régimen de tipos de cambio flotantes, que genera ganancias especulativas.

En el caso concreto de la IED, el correspondiente aumento de los flujos adopta una gama muy amplia de formas, entre las que se encuentran las siguientes: la expansión de las relaciones comerciales; flujos de préstamos y financiamiento entre empresas; la transmisión de tecnología y la transferencia de activos mediante fusiones y adquisiciones.

En referencia a los datos empíricos sobre la exactitud de los flujos de IED, existe una importante advertencia sobre la naturaleza de este capital en relación con la clasificación de las empresas multinacionales, que Michalet (1985) define como una empresa (o un grupo), generalmente de gran tamaño, que, partiendo de una base nacional, ha creado varias sucursales en el extranjero en varios países, siguiendo una estrategia y una organización concebidas a escala mundial (citado en Chesnais, 1996, pág. 73). Según Chesnais (1996, pág. 73), esta definición sigue siendo útil en varios aspectos, pues señala que la empresa multinacional comenzó invariablemente como una gran empresa a nivel nacional, lo que significa también que es el resultado de un proceso más o menos largo y complejo de concentración y centralización del capital, y que a menudo se diversificó antes de comenzar a internacionalizarse; que la empresa multinacional tiene un origen nacional, por lo que los puntos fuertes y débiles de su base nacional y la ayuda que ha recibido de su Estado serán componentes de su estrategia y su competitividad; que esta empresa es generalmente un grupo cuya forma jurídica contemporánea es la de un holding internacional; y, por último, que este grupo actúa a escala mundial y dispone de estrategias y de una organización creadas para ello.

En general, esta discusión muestra que la integración funcional de las empresas multinacionales se ha convertido en una característica fundamental del actual escenario económico internacional, que se basa cada vez más en una cadena de producción que interconecta una secuencia de funciones operativas, cada una de las cuales añade valor al proceso de producción de bienes y servicios.

Las cadenas de producción creadas por las empresas multinacionales tienen la capacidad de coordinar y controlar las operaciones en más de un país. Para ello, desarrollan mecanismos cada vez más sofisticados de relaciones intra- e interorganizativas, que configuran las características del sistema económico actual.

Como la actividad de las empresas multinacionales implica decisiones sobre la exportación o la internalización del proceso de producción, también hay que reconocer que este movimiento actual se apoya en diferentes formas de coordinación. Representan auténticas redes de relaciones dentro de las empresas y entre ellas, ya que la jerarquía del sistema económico está estructurada sobre la base de diferentes grados de poder e influencia. En consecuencia, estas redes se consideran dinámicas y en continuo estado de mutación.

Sin embargo, las decisiones de inversión, expresadas en las tendencias recientes de los flujos de IED, muestran que las fronteras nacionales siguen siendo relevantes en términos de política económica global, ya que son uno de los principales determinantes de las elecciones de localización de las empresas, y tienen una influencia directa en los flujos de IED. 
En consecuencia, los Estados han tratado de actuar cada vez más en el sistema internacional con el objetivo de influir en las elecciones geográficas de las empresas multinacionales. Entre las principales expresiones de este proceso se encuentran las condiciones ofrecidas a las empresas multinacionales en términos de acceso al mercado nacional y a los factores de producción.

Otro punto importante relacionado con el desempeño de las empresas multinacionales es el propio proceso de establecimiento de sucursales en el extranjero, que, como se ha señalado anteriormente, suele producirse por las siguientes razones: i) la posibilidad de explotar materias primas situadas en el país de destino; ii) la entrada en el mercado nacional, que permite la sustitución de las importaciones, y iii) convertir el país de destino en una plataforma de exportación de productos intermedios o acabados.

Un análisis del volumen de IED en 2016 muestra que el 63,3\% del capital en cuestión se canalizó hacia países desarrollados (UNCTAD, 2020). Sin embargo, no se puede negar el esfuerzo por crear un mercado global, en el que los países en desarrollo, como bloque, absorbieron el 34\% del volumen total de IED en el mismo período.

Si se mide en términos de entradas, los Estados Unidos son el principal receptor de IED, con un 23,9\% del volumen total, mientras que América Latina tiene una cuota del 7,3\%; de ahí la elección de los países analizados en este estudio.

En cuanto a las salidas, los países desarrollados representaron el 76,3\% del volumen de IED en 2016, mientras que los países en desarrollo representaron el 22,2\% y los países latinoamericanos, el 2,2\%.

Las redes de relaciones que existen entre las empresas nacionales y las multinacionales suelen ser más densas y extensas en las economías desarrolladas que en las economías en desarrollo. Además, en este último caso, esos vínculos tienden a producirse en las economías más grandes e industrializadas. Sin embargo, la mayor parte de los flujos de IED se destinan solo a un puñado de países en desarrollo, en particular a los países recientemente industrializados, y especialmente a China ${ }^{1}$. En este grupo, solo nueve países representaron el 53,1\% del total de la IED destinada a los países en desarrollo en 2012. Algunos de esos países se analizan en este estudio, no solo desde el punto de vista de la IED. También se evalúa la exportación de capital de inversión a otros países, así como las relaciones entre estos flujos reveladas a través de un indicador que identifica el patrón de "importación-exportación" de la actividad productiva, cuya justificación se proporciona en el marco teórico descrito a continuación.

En este contexto, el presente estudio evalúa la importancia relativa de utilizar el índice Grubel y Lloyd (GL) para revelar las tendencias de comportamiento de la IED de cuatro países latinoamericanos (Argentina, Brasil, Chile y México) entre 1995 y 2016.

El cálculo del índice GL de estos cuatro países revela su modesta participación en las "exportaciones" totales de capital productivo (IED). Además, en los casos de la Argentina y el Brasil, las entradas fluctúan mucho, por lo que el índice GL sugiere un grado de internacionalización de la producción errático y muy inferior al registrado por los países desarrollados y China, que es el bloque de países en desarrollo utilizado para las comparaciones en este grupo. En cambio, Chile y México tienen un índice GL mucho más alto que la Argentina y el Brasil, por lo que muestran una mayor apertura que estos dos países, pero menor que la de los países desarrollados y China.

En la sección II de este estudio se analiza la relación entre la IED y la economía política internacional, y se evalúan los flujos y volúmenes del capital en cuestión, tanto desde el punto de vista de los países receptores (IED entrante) como de los países de origen (IED saliente). En la sección III se describe la metodología aplicada en la investigación con el índice GL. En la sección IV se aplica el índice a las entradas y salidas de IED de cuatro países: Argentina, Brasil, Chile y México. La elección de los países se justifica por la prominencia de sus economías en relación con otros países en términos de entrada de IED, ya que la muestra incluye los cuatro principales receptores de IED en América Latina. Por último, en la sección $\vee$ se exponen las conclusiones finales.

\footnotetext{
1 Este grupo comprende los siguientes países: Brasil, China, Filipinas, India, Malasia, México, Sudáfrica, Tailandia y Turquía.
} 


\section{Economía política internacional y flujos mundiales de IED}

Las condiciones del sistema internacional muestran que el fin de la bipolaridad y el crecimiento de las relaciones comerciales y financieras han dado paso a una nueva fase de las relaciones internacionales. A pesar de las afirmaciones en contrario, estas siguen siendo apoyadas en gran medida por el Estado, especialmente en los países centrales o desarrollados. Sin embargo, el grado de complejidad e interdependencia de las relaciones políticas y económicas internacionales, derivado de la interconexión global de las actividades productivas de las empresas multinacionales, hace que esta realidad sea diferente en cada caso.

En general, no hay grandes desacuerdos en los análisis de estas transformaciones a la hora de evaluar el crecimiento de los flujos económicos, culturales y sociales, porque el hecho de que las sociedades estén cada vez más interrelacionadas es una cuestión de amplio consenso. También hay una convergencia de ideas en cuanto a la importancia del uso de las nuevas tecnologías de la información, que permiten que las interacciones se produzcan a una velocidad y escala cada vez mayores, contribuyendo así a una reducción de los espacios reales entre las diferentes esferas y actores del escenario internacional. Un amplio sector de las ciencias sociales asume que ha prevalecido un amplio proceso de interconexión global basado en relaciones materiales, normativas y simbólicas.

Lo que se percibe invariablemente en los debates sobre la globalización son puntos de vista que aprueban o desaprueban este proceso, y se ha producido un extenso conjunto de trabajos que lo critican o lo apoyan y, por tanto, refutan o mantienen esta realidad. Hasta cierto punto, las posiciones sobre la globalización se dividen entre escépticos y globalistas.

Sin embargo, más allá de la tradicional división entre globalistas y escépticos del debate teórico sobre la globalización, existe una tercera alternativa, denominada transformacionista, que pretende fusionar elementos presentes en las dos posiciones extremas y ofrecer una propuesta analítica que refleje mejor la complejidad real del sistema internacional.

Martell (2007) sostiene que el transformacionismo busca criticar a los hiperglobalistas, partiendo de la realidad de que la globalización es una verdad inexorable. En consecuencia, sus reflexiones sobre este proceso encuentran muchos puntos de conexión con la perspectiva escéptica.

Sin embargo, partiendo de la premisa de que no se puede subestimar la importancia de las políticas liberales, los transformacionistas afirman que el análisis del sistema internacional actual debe tener en cuenta el hecho de que, a pesar de mantener una centralidad relativa en la tríada de países del grupo central, la integración de la economía mundial se ha extendido más allá de este grupo, especialmente a países como China y el Brasil.

A este respecto, Hay y Marsh (2000) ofrecen una revisión crítica de algunas de las posiciones escépticas, señalando que sus concepciones son a menudo algo exageradas. Por ello, proponen un enfoque multidimensional del proceso de globalización, que se desarrolla de forma compleja y desigual. Así, la globalización no se vería como un proceso con un estado final, sino como una tendencia frente a la cual surgen una serie de contratendencias.

Por ejemplo, los aspectos territoriales de la realidad internacional se siguen considerando centrales en la dinámica del sistema, pero se pone en duda la idea de que esto sea la base de la vida moderna. Las cuestiones económicas, sociales y políticas, si bien están vinculadas a un territorio, también forman parte de un proceso de desterritorialización. Como ejemplo de ello, las actividades de las empresas multinacionales, sin dejar de mantener los vínculos territoriales, buscan cada vez más nuevas bases comerciales y de producción más allá de sus fronteras nacionales. Según Martell (2007), una cuestión relacionada se refiere a la perspectiva exclusivamente cuantitativa del análisis de la 
realidad que hacen los escépticos. Sin embargo, comprender la etapa actual de la globalización también implica evaluar los datos cualitativos, a través de un análisis que considere la naturaleza individualizada e interpretativa de todo el proceso.

En la práctica, esto significa que no basta con cuantificar el valor de los bienes y capitales comercializados, o el número de personas que se desplazan a nivel internacional, sino que, sobre todo, es esencial evaluar el impacto cualitativo de los flujos migratorios, comerciales y financieros en la economía, la política y la cultura de cada país a lo largo del tiempo.

Desde esta perspectiva, la globalización implica nuevos patrones de estratificación entre las sociedades y dentro de ellas, de modo que surgen nuevas configuraciones a partir de patrones distintos a los de la dicotomía tradicional "centro-periferia", ya que se están desarrollando islas de excelencia - sectores tecnológicos, financieros y productivos - en varios países emergentes, especialmente en Asia y América Latina.

Estas relaciones deben evaluarse teniendo en cuenta las diferentes formas de transmisión del poder económico, especialmente en lo que se refiere a la creación de un continuo espacial, la expansión de las relaciones comerciales, el aumento de la liquidez internacional, los mayores flujos de factores de producción e información, y el entrelazamiento de las cuestiones culturales, entre otras.

Estas consideraciones plantean también la necesidad de repensar el papel de las entidades territoriales (Estados o bloques de poder regionales), pero desde una lógica convergente con los intereses puramente capitalistas.

Este parece ser un punto central para entender el principal enfoque analítico de esta investigación, es decir, los flujos de IED en el Brasil y otros países seleccionados, ya que pone de manifiesto una relación entre el capital y las decisiones políticas internas de un país en un momento en que el flujo de capital ha crecido significativamente en los últimos 20 años.

En este sentido, la integración funcional de las empresas multinacionales ha sido fundamental para caracterizar el contexto actual de la globalización, que se basa cada vez más en una cadena de producción que interconecta una secuencia de funciones operativas, en la que cada etapa añade valor al proceso de producción de bienes y servicios. A su vez, esta cadena de producción plantea la necesidad de comprender dos cuestiones importantes: cómo se coordina y regula, y su configuración geográfica.

En cuanto al primer punto, las cadenas de producción establecidas por las empresas multinacionales se caracterizan por su poder para coordinar y controlar las operaciones en más de un país y han desarrollado mecanismos cada vez más sofisticados de relaciones intra- e interorganizacionales, configurando las características del sistema económico actual.

Por otra parte, todas las organizaciones empresariales, incluidas las multinacionales más globales, operan dentro de algún tipo de sistema regulatorio, ya que están sujetas a las leyes nacionales, aunque intenten actuar con el claro objetivo de aprovecharse de estas regulaciones.

El resultado de esta relación, como señala Strange (1979), es una ampliación de la complejidad de las relaciones que intervienen en las decisiones empresariales, estableciendo una lógica de juegos entre empresas y Estados configurada básicamente en una interacción triangular: empresa-empresa, Estado-Estado y empresa-Estado. Esta configuración de la realidad, según Dicken (1998), es responsable de una nueva "geoeconomía", que está en constante proceso de reestructuración y es producida por las acciones tanto de las empresas como de los Estados, formando una maraña de relaciones dinámicas.

En consecuencia, las decisiones de inversión, expresadas en las tendencias recientes de los flujos de IED, muestran que las fronteras nacionales siguen constituyendo las verdaderas diferencias de la política económica mundial, ya que son uno de los principales determinantes de las elecciones de localización de las empresas, condiciones que influyen directamente en el flujo de este capital. 
En consecuencia, los Estados han tratado de actuar cada vez más en el sistema internacional con el objetivo de influir en las elecciones geográficas de las empresas multinacionales. Entre las principales expresiones de este proceso se encuentran las condiciones ofrecidas a las empresas transnacionales en términos de acceso al mercado nacional y a los factores de producción.

Las empresas multinacionales pueden establecerse implantando nuevos procesos y plantas de producción, pero también pueden hacerlo mediante fusiones y adquisiciones. A este respecto, conviene evaluar si los flujos de IED han permitido de hecho la reestructuración económica de muchos países en desarrollo, lo que puede implicar la mejora de la productividad de algunas de sus actividades.

El precio que paga un país por participar en este juego depende del número de empresas extranjeras independientes que compiten por la oportunidad de inversión, de la importancia que tiene para el país la empresa multinacional que se va a establecer y del nivel de necesidad nacional que se percibe de dicha contribución.

Las empresas multinacionales, a su vez, tienden a basar sus decisiones en el atractivo de la oportunidad de inversión específica que ofrece el país anfitrión a cambio de oportunidades similares encontradas en otros países, las condiciones económicas del país anfitrión, especialmente su posición en el mercado, y su grado de estabilidad política.

Así, se concluye que los principales componentes de la relación de negociación entre las empresas multinacionales y los países de acogida se basan en sus recursos de poder. Además, ambos operan bajo ciertas condicionalidades que tienden a restringir el alcance del ejercicio de estos recursos.

Esta expansión de los flujos de capital en el sistema económico internacional habla en gran medida de la falsa noción de que la IED se ha convertido en algo preferible a la inversión de cartera y a los préstamos bancarios. En general, esta opinión de que la IED no está sujeta a los caprichos de otros tipos de capital financiero se deriva en parte de los ejemplos extraídos de los modelos de desarrollo de los países asiáticos en la década de 1990, que se sabe que han estado estrechamente vinculados a la IED.

Uno de los principales argumentos utilizados para difundir la idea de que la atracción de IED es la forma de financiamiento más adecuada es asociarla a las inversiones de capital fijo, que no tienen liquidez inmediata, a diferencia de las inversiones en carteras públicas o privadas.

Sin embargo, para Kregel (1996), estas distinciones no son propias de los países en desarrollo en la actualidad, por lo que este capital no debe evaluarse necesariamente desde una perspectiva a largo plazo. Esto se debe a que generalmente se ignora la intensidad e importancia de los procesos de fusión y adquisición dominados por los países desarrollados. En esta perspectiva, el autor considera que la innovación en los mercados financieros convierte el capital de muchas empresas en una verdadera mercancía que se negocia a diario.

Además, las innovaciones en el mercado financiero internacional han permitido el desarrollo de métodos de cobertura, incluidas las transacciones de IED en activos fijos, de modo que una operación puede no implicar directamente al inversor en acciones que afecten al tipo de cambio, y ni siquiera en transacciones que impliquen al mercado de capitales.

Es en este contexto en que el Brasil y, según esta investigación, los demás países seleccionados, se han consolidado como actores con cierto protagonismo en el sistema internacional. El primer objetivo de estos actores es expresarse como líderes entre los países en desarrollo, y un segundo objetivo es abrir un espacio destacado de participación en el contexto de la globalización.

Dado que el objetivo principal de esta investigación es analizar el flujo de capitales hacia la Argentina, el Brasil, Chile y México entre 1995 y 2016 a través del índice Grubel-Lloyd, se utilizará el concepto de IED definido por la Conferencia de las Naciones Unidas sobre Comercio y Desarrollo (UNCTAD) (UNCTAD, 2020), que caracteriza estas inversiones como operaciones destinadas a contratar un negocio 
duradero en el país de origen del titular de dicho capital. Por lo tanto, la IED requiere la existencia de una sede y una filial fuera de la sede, lo que lleva a su funcionamiento conjunto, convirtiéndola en una empresa multinacional. También requiere una relación de control total de la sede sobre la filial fuera de la frontera a la que pertenece el capital; este control se manifiesta en la propiedad de al menos el $10 \%$ de las acciones ordinarias o de los derechos de voto de una sociedad, o su equivalente para las empresas privadas.

Una vez establecida esta definición, se puede afirmar que los flujos de IED, en términos de las cantidades internalizadas por los países receptores de este capital, crecieron intensamente en la década de 1990. La tendencia ha sido a crecer ininterrumpidamente incluso durante las crisis económicas internacionales de principios de la década de 2000 y la crisis de 2008. Un año antes de la crisis de 2008, el flujo total de IED absorbido por los distintos países receptores rondaba los 2 billones de dólares (a precios corrientes). En este nuevo contexto de crisis, los flujos se han comportado de forma errática, lo que ha provocado una disminución de los flujos globales, en comparación con 2007, como se muestra en el gráfico 1.

Gráfico 1

Entradas de inversión extranjera directa a nivel mundial, 1970-2016

(En miles de millones de dólares a precios corrientes)

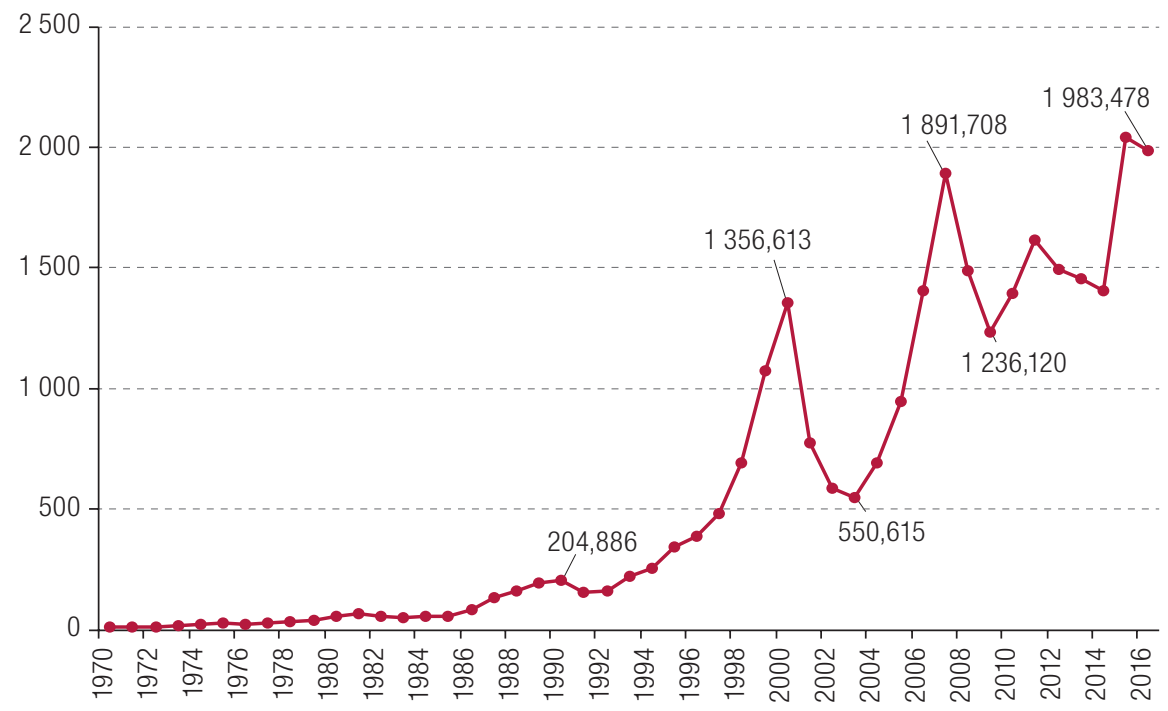

Fuente: Conferencia de las Naciones Unidas sobre Comercio y Desarrollo (UNCTAD).

Un análisis de estos flujos de los países receptores durante el período de estudio (1995-2016) muestra que los países desarrollados recibieron el 59,7\% de la IED mundial, mientras que los países en desarrollo absorbieron el 36,6\% y los "países en transición", el 3,6\%. Además de la evidencia del predominio de los países desarrollados como destino de estos capitales, solo la economía de los Estados Unidos recibió el 16,9\% del flujo total en el período en cuestión.

Aparte de China, el Brasil es el país en desarrollo que más IED recibió: un 2,7\% del total entre 1995 y 2016, por un monto total de 836.300 millones de dólares. Las participaciones y los montos recibidos por los demás países estudiados en este artículo - México, Chile y Argentina - se muestran en el cuadro 1. También hay que señalar que los cuatro países de la muestra (Argentina, Brasil, Chile y México) representan el 75,5\% del flujo total absorbido por los países de América Latina y el Caribe durante el período analizado. 


\section{Cuadro 1}

Países y agrupaciones seleccionados:

total de entradas de inversión extranjera directa, 1995 a 2016

(En miles de millones de dólares a precios corrientes)

\begin{tabular}{|c|c|c|c|}
\hline Clasificación & País 0 agrupación & $\begin{array}{l}\text { Miles de millones } \\
\text { de dólares }\end{array}$ & Porcentaje del total \\
\hline \multirow[t]{5}{*}{-} & Total & 24785,947 & 100,00 \\
\hline & Economías desarrolladas & 14801,062 & 59,72 \\
\hline & Economías en desarrollo & 9069,407 & 36,59 \\
\hline & Economías en transición & 910,920 & 3,68 \\
\hline & América Latina y el Caribe & 2328,583 & 9,39 \\
\hline $1^{0}$ & Estados Unidos & 4188,608 & 16,9 \\
\hline $2^{0}$ & China & 1778,229 & 7,2 \\
\hline $3^{\circ}$ & Reino Unido & 1716,856 & 6,9 \\
\hline $4^{0}$ & Hong Kong (China) & 1156,861 & 4,7 \\
\hline $5^{0}$ & Bélgica & 887,680 & 3,6 \\
\hline $6^{\circ}$ & Alemania & 850,854 & 3,4 \\
\hline $7^{\circ}$ & Brasil & 836,311 & 3,4 \\
\hline $8^{\circ}$ & Países Bajos & 810,011 & 3,3 \\
\hline $9^{\circ}$ & Canadá & 803,538 & 3,2 \\
\hline $10^{\circ}$ & Singapur & 714,095 & 2,9 \\
\hline $16^{\circ}$ & México & 508,987 & 2,1 \\
\hline $24^{\circ}$ & Chile & 237,432 & 1,0 \\
\hline $31^{\circ}$ & Argentina & 174,413 & 0,7 \\
\hline
\end{tabular}

Fuente: Conferencia de las Naciones Unidas sobre Comercio y Desarrollo (UNCTAD).

El análisis de los flujos de IED en función de su origen muestra que el 78,4\% del capital procede de países desarrollados, mientras que el 19,2\% proviene de países en desarrollo y el 2,4\%, de países en transición.

El principal "exportador" de IED son los Estados Unidos, que aportan casi una quinta parte del monto total. A los Estados Unidos le siguen las principales economías de Europa, así como el Japón, Hong Kong (China) y el Canadá.

El Brasil, a pesar de estar entre las mayores economías del mundo, envía una parte relativamente pequeña de la IED a otros países, como también ocurre con México, Chile y la Argentina; estos países generaron el 1,5\% del total de salidas de IED y el 76,6\% del total enviado por los países de América Latina y el Caribe en el período analizado, como se muestra en el cuadro 2.

Si se comparan los flujos de IED recibidos por los cuatro países de la muestra con el tamaño de sus economías, la relación entre IED y PIB entrante de Chile fue muy superior a la de las otras economías analizadas (Argentina, Brasil y México), además de ser significativamente superior a la misma relación registrada en el caso del grupo de países en desarrollo.

Mientras que, en los casos de la Argentina, el Brasil y México, este indicador mostró un promedio del 1,9\%, el 2,9\% y el 2,6\%, respectivamente, y, en el de los países en desarrollo, del 3,2\%, la relación entre entrada de IED y PIB en Chile fue del 7,6\% en promedio entre 2007 y 2016, como se muestra en el gráfico 2. 


\section{Cuadro 2}

Países y agrupaciones seleccionados:

total de salidas de inversión extranjera directa, 1995 a 2016

(En miles de millones de dólares a precios corrientes)

\begin{tabular}{llrc}
\hline \multirow{2}{*}{ Clasificación } & País o agrupación & $\begin{array}{c}\text { Miles de millones } \\
\text { de dólares }\end{array}$ & Porcentaje del total \\
\hline \multirow{2}{*}{} & Total & 24017,089 & 100,00 \\
\cline { 2 - 4 } & Economías desarrolladas & 18 827,930 & 78,39 \\
\cline { 2 - 4 } & Economías en desarrollo & 4605,962 & 19,18 \\
\cline { 2 - 4 } & Economías en transición & 575,905 & 2,40 \\
\cline { 2 - 4 } & América Latina y el Caribe & 469,802 & 1,96 \\
\hline $1^{\circ}$ & Estados Unidos & 4859,109 & 20,2 \\
\hline $2^{\circ}$ & Reino Unido & 1669,128 & 6,9 \\
\hline $3^{\circ}$ & Alemania & 1506,727 & 6,3 \\
\hline $4^{\circ}$ & Japón & 1478,278 & 6,2 \\
\hline $5^{\circ}$ & Países Bajos & 1323,072 & 5,5 \\
\hline $6^{\circ}$ & Francia & 1303,535 & 5,4 \\
\hline $7^{\circ}$ & Hong Kong (China) & 1104,116 & 4,6 \\
\hline $8^{\circ}$ & China & 971,487 & 4,0 \\
\hline $9^{\circ}$ & Canadá & 924,251 & 3,8 \\
\hline $10^{\circ}$ & España & 885,227 & 3,7 \\
\hline $31^{\circ}$ & México & 123,055 & 0,5 \\
\hline $32^{\circ}$ & Chile & 121,941 & 0,5 \\
\hline $35^{\circ}$ & Brasil & 86,536 & 0,4 \\
\hline $50^{\circ}$ & Argentina & 28,128 & 0,1 \\
\hline
\end{tabular}

Fuente: Conferencia de las Naciones Unidas sobre Comercio y Desarrollo (UNCTAD).

\section{Gráfico 2}

Países seleccionados:

entradas de inversión extranjera directa como porcentaje del PIB, 2007-2016 (En porcentajes)

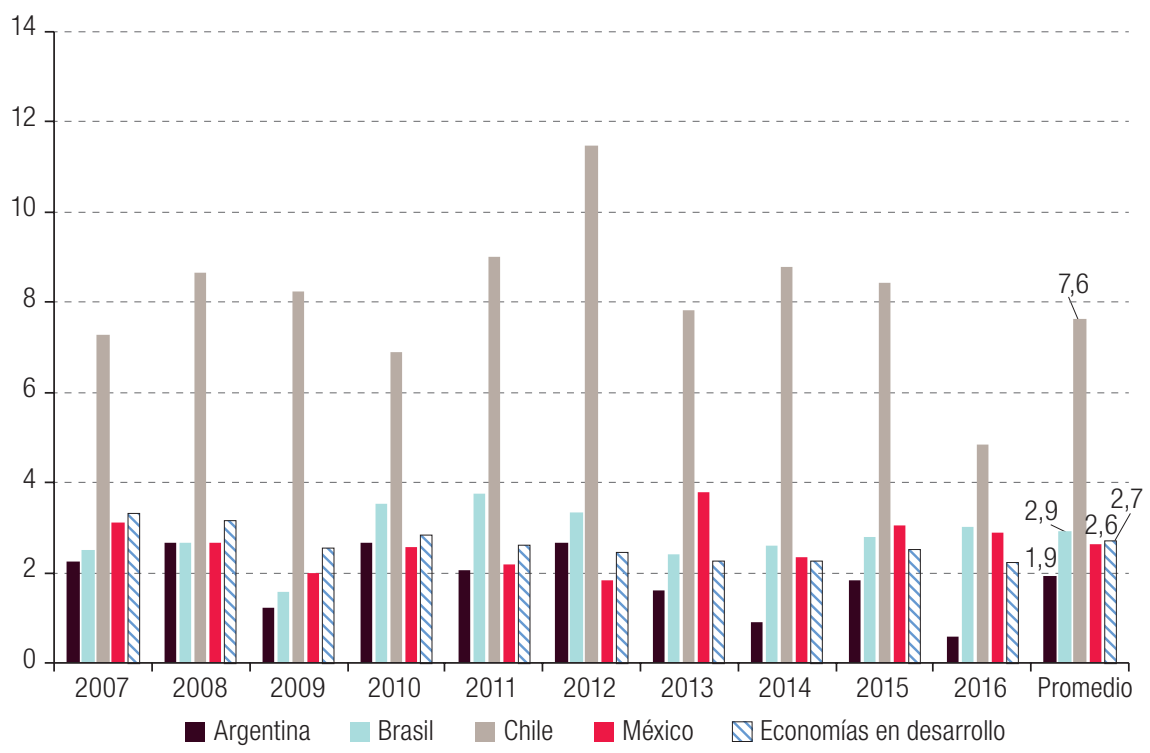

Fuente: Conferencia de las Naciones Unidas sobre Comercio y Desarrollo (UNCTAD). 
Se observa un comportamiento similar en las salidas de IED de los países de la muestra, ya que Chile también presenta una relación entre IED y PIB mucho más elevada que la Argentina, el Brasil, México y los países en desarrollo, como se muestra en el gráfico 3.

\section{Gráfico 3}

Países seleccionados:

salidas de inversión extranjera directa como porcentaje del PIB, 2007-2016

(En porcentajes)

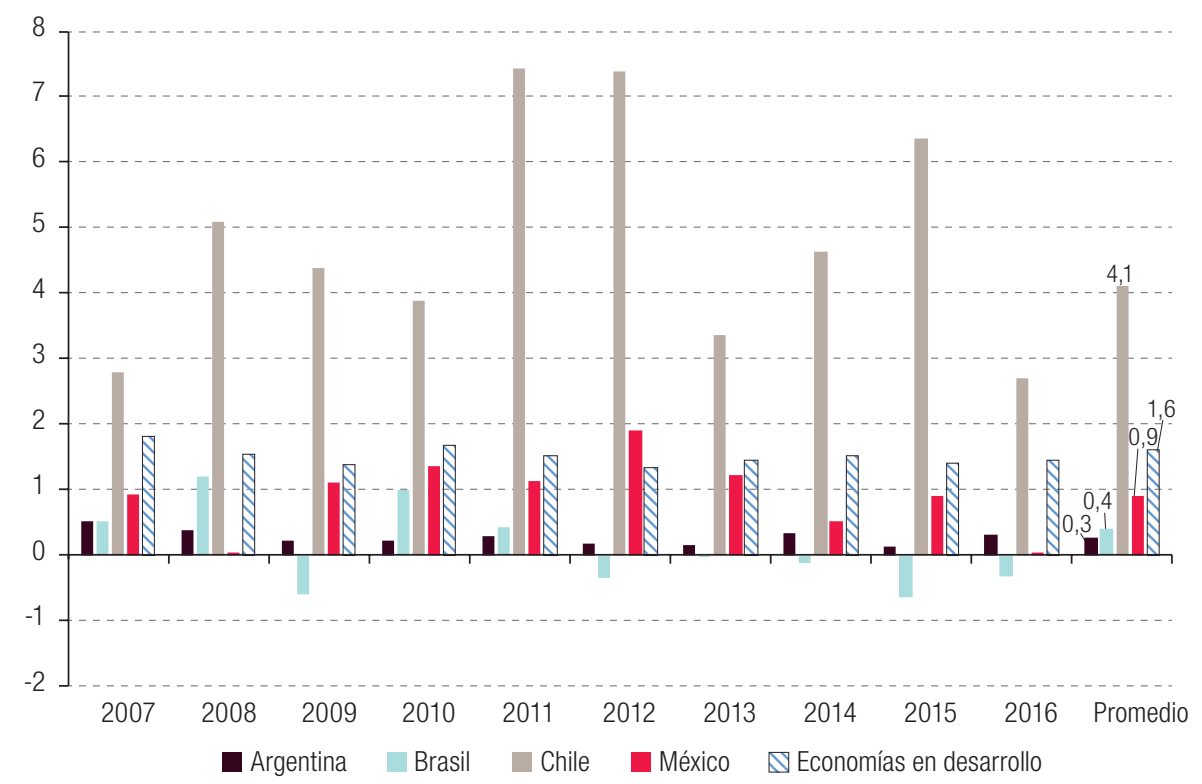

Fuente: Conferencia de las Naciones Unidas sobre Comercio y Desarrollo (UNCTAD).

La proporción de IED varía de un país a otro, tanto entre los diez mayores países receptores de IED como entre los cuatro países de la muestra. La importancia de las empresas extranjeras en la economía de Hong Kong (China) queda claramente demostrada por el hecho de que su relación entre volumen de IED y PIB es superior a 4. Los Estados Unidos presentan una proporción similar a la observada en el grupo de países desarrollados, que a su vez también se aproxima a la misma medida en el caso de los países en desarrollo.

En los cuatro países de la muestra, el volumen de IED de Chile representa casi el 101,1\% del $\mathrm{PIB}$, lo que muestra la gran importancia del capital extranjero para su actividad económica, mientras que las cifras equivalentes en los otros países son las siguientes: Brasil, un 39,2\%; México, un 44,0\%, y la Argentina, un 13\% (véase el cuadro 3). 


\section{Cuadro 3}

Países y agrupaciones seleccionados:

volumen de inversión extranjera directa en relación con el PIB, 2016

(En porcentajes)

\begin{tabular}{llc}
\hline Clasificación & País o agrupación & IED/PIB \\
\hline- & Mundo & 36,1 \\
\hline- & Economías en desarrollo & 31,7 \\
\hline- & Economías desarrolladas & 39,6 \\
\hline- & Economías en transición & 42,1 \\
\hline- & América Latina y el Caribe & 40,5 \\
\hline $1^{\circ}$ & Estados Unidos & 35,0 \\
\hline $2^{\circ}$ & China & 12,1 \\
\hline $3^{\circ}$ & Reino Unido & 55,7 \\
\hline $4^{\circ}$ & Hong Kong (China) & 506,68 \\
\hline $5^{\circ}$ & Bélgica & 106,9 \\
\hline $6^{\circ}$ & Alemania & 22,6 \\
\hline $7^{\circ}$ & Brasil & 39,2 \\
\hline $8^{\circ}$ & Países Bajos & 107,1 \\
\hline $9^{\circ}$ & Canadá & 63,68 \\
\hline $10^{\circ}$ & Singapur & 378,3 \\
\hline $16^{\circ}$ & México & 44,0 \\
\hline $24^{\circ}$ & Chile & 101,1 \\
\hline $31^{\circ}$ & Argentina & 13,0 \\
\hline
\end{tabular}

Fuente: Conferencia de las Naciones Unidas sobre Comercio y Desarrollo (UNCTAD).

En el resto de este artículo, se analizará brevemente el crecimiento económico de los diez mayores receptores de IED y de los cuatro países de la muestra (Argentina, Brasil, Chile y México) utilizando el índice Grubel-Lloyd (GL).

La intención no es inferir ninguna relación entre los flujos de IED y la actividad económica en estos países, sino simplemente hacer un análisis descriptivo conciso de la variación de sus PIB reales.

Como es sabido, China, el tercer mayor receptor de IED durante el período analizado, ha registrado tasas de crecimiento económico muy superiores a la media mundial. Sin embargo, es imposible inferir la importancia de la IED en la actividad económica china a través de esta simple evaluación; el mero hecho de que el país sea un importante receptor de este tipo de capital no demuestra que la entrada de empresas multinacionales extranjeras en el país deba ser un componente importante que contribuya a ello.

Cuando se evalúa el crecimiento del resto de los principales países receptores, el comportamiento de su actividad económica es similar a la media mundial. En los cuatro países de la muestra, Chile vuelve a ser el caso más destacado, con una tasa de crecimiento económico muy superior a la de los demás países, y también a la media mundial. En este sentido, cabe destacar la importancia de la IED en la economía chilena, que representa cerca del 60\% del PIB. El Brasil y la Argentina también registraron tasas de crecimiento del PIB real superiores a la media mundial, mientras que el crecimiento en México fue inferior. En el cuadro 4 se presentan detalles adicionales. 


\section{Cuadro 4}

Diez principales receptores de IED y otros países seleccionados: crecimiento económico acumulado y promedio, 1995-2016

(En porcentajes)

\begin{tabular}{llcc}
\hline $\begin{array}{l}\text { Clasificación de las } \\
\text { entradas de IED }\end{array}$ & País & $\begin{array}{c}\text { Variación acumulada } \\
\text { del PIB real } \\
\text { (en porcentajes) }\end{array}$ & $\begin{array}{c}\text { Crecimiento promedio } \\
\text { del PIB real, 1995-2016 } \\
\text { (en porcentajes) }\end{array}$ \\
\hline- & Mundo & 88,94 & 2,93 \\
\hline $1^{\circ}$ & Estados Unidos & 70,29 & 2,45 \\
\hline $2^{\circ}$ & China & 630,35 & 9,46 \\
\hline $3^{\circ}$ & Reino Unido & 63,31 & 2,25 \\
\hline $4^{\circ}$ & Hong Kong (China) & 113,14 & 3,50 \\
\hline $5^{\circ}$ & Bélgica & 55,21 & 2,02 \\
\hline $6^{\circ}$ & Alemania & 43,55 & 1,66 \\
\hline $7^{0}$ & Brasil & 78,95 & 2,68 \\
\hline $8^{\circ}$ & Países Bajos & 66,82 & 2,35 \\
\hline $9^{\circ}$ & Canadá & 84,98 & 2,84 \\
\hline $10^{\circ}$ & Singapur & 239,63 & 5,72 \\
\hline $16^{\circ}$ & México & 85,12 & 2,84 \\
\hline $24^{\circ}$ & Chile & 180,13 & 4,79 \\
\hline $31^{\circ}$ & Argentina & 82,96 & 2,78 \\
\hline
\end{tabular}

Fuente: Banco Mundial.

Una vez descritos los flujos recientes de IED en el mundo y, en particular, en la Argentina, el Brasil, Chile y México, los siguientes apartados tratarán de ampliar la comprensión de este tema a partir de la discusión metodológica y el cálculo del índice GL de las cuatro economías en cuestión y del grupo de países desarrollados.

Dicho índice representa una alternativa metodológica con potencial para proporcionar una nueva interpretación de estos movimientos de capital, observando que los resultados muestran una tendencia específica en el grupo de países en desarrollo. Además de las otras características ya descritas a lo largo de esta sección, esto puede contribuir al debate sobre la IED desde el punto de vista de la economía política internacional desarrollado en este trabajo.

\section{El índice Grubel-Lloyd}

El índice Grubel-Lloyd (GL) se volvió muy conocido a finales de los años setenta con la investigación de los determinantes de los patrones comerciales entre países, tras numerosos intentos de explicar estos determinantes tanto teórica como empíricamente, desde el modelo ricardiano hasta las modernas teorías del comercio internacional que consideran los mercados imperfectamente competitivos y la aparición de economías de escala como un importante motor del comercio. La teoría de la ventaja comparativa de Ricardo demostró que un país debe especializarse en la producción de bienes que implican un costo de oportunidad relativamente menor que el de otros países. Esta importante explicación se complementó con el modelo de Heckscher-Ohlin-Samuelson, según el cual un país tiene ventajas comparativas en los bienes cuya producción hace un uso intensivo de un factor de producción que es abundante en el país. Las conclusiones de los modelos ricardianos y de Heckscher-Ohlin-Samuelson implican que los países comercian con diferentes productos en el comercio internacional.

En modelos más recientes, como los de Krugman (1979 y 1980), surge un factor adicional como determinante del patrón de comercio entre países. La diferenciación de productos, una característica de los mercados imperfectamente competitivos, explica por qué distintos países comercian con productos 
similares. Los modelos anteriores no contemplaban esta posibilidad. La presencia de economías de escala, combinada con la diferenciación de productos característica de los mercados imperfectamente competitivos, no estaba presente en los modelos comerciales tradicionales y representa una parte sustancial del comercio de un país con el resto del mundo. En otras palabras, mientras que la teoría de la ventaja comparativa y el modelo de Heckscher-Ohlin-Samuelson explican por qué un país exporta productos agrícolas e importa productos manufacturados, la tesis de la diferenciación de productos explica cómo dos países comercian con el mismo tipo de producto, como los automóviles.

Puede considerarse que el comercio internacional consta de dos partes: el comercio interindustrial y el comercio intraindustrial. El primero se refiere al patrón de comercio explicado por las ventajas comparativas y el modelo de proporción de factores. En cambio, el comercio intraindustrial se debe a la existencia de mercados imperfectos, lo que constituye una importante fuente de ganancias para el comercio, en la medida en que permite obtener ganancias de escala en productos diferenciados.

Así pues, el comercio interindustrial viene determinado por la abundancia de uno o varios factores de producción en un país. Los países con abundancia de capital tienden a exportar productos intensivos en capital, como tecnología y medicamentos. Por el contrario, los países con abundancia de tierras tienden a exportar principalmente productos agrícolas. A diferencia del comercio interindustrial, el comercio intraindustrial es imprevisible, aunque es posible identificar una serie de factores que contribuyen a su aparición. Un hecho relevante se refiere a las características subyacentes de los países en cuestión. Por ejemplo, si dos países tienen una cuota de factores idéntica, no habrá comercio interindustrial entre ellos. En cambio, es probable que haya comercio intraindustrial, ya que las economías de escala son una fuente importante de beneficios comerciales.

Para calcular el comercio intraindustrial, uno de los índices más utilizados es el de Grubel y Lloyd (1975), que se ha aplicado con frecuencia en los estudios de comercio internacional, principalmente durante la década de 1980, y se presenta en la literatura reciente en el siguiente formato:

$$
I G L_{C I}=\frac{\sum_{i=1}^{n}\left(x_{i}+m_{i}\right)-\sum_{i=1}^{n}\left|x_{i}-m_{i}\right|}{\sum_{i=1}^{n}\left(x_{i}+m_{i}\right)} \text { en que } 0 \leq I G L_{C I} \leq 1
$$

donde:

$I G L_{C I}=$ índice de comercio intraindustrial en el sector

$x_{i} \quad=$ exportaciones del producto o sector

$m_{i} \quad$ importaciones del producto o sector

La ecuación original de Grubel-Lloyd se expresa como el resultado de la ecuación (1) multiplicado por 100, lo que significa que el resultado estará siempre en el intervalo [1, 100]. Sin embargo, en estudios recientes, se eliminó el factor y el resultado comenzó a darse en el intervalo [0, 1]. Así, cuando el valor de las exportaciones de una determinada industria es similar al valor de las importaciones, el resultado del índice será cercano a 1. Por el contrario, cuanto mayor sea la diferencia de valor entre las exportaciones y las importaciones, más se acercará el resultado del índice a 0 . Un resultado cercano a 0 indica la existencia de comercio interindustrial, basado, por ejemplo, en ventajas comparativas o en la abundancia de factores de producción.

Al analizar las posibles fronteras de la investigación del comercio intraindustrial, Herbert Grubel, uno de los creadores del índice, sugirió que el índice GL podría aplicarse perfectamente a la balanza de pagos de un país (Grubel, 2002). El autor sostuvo que los flujos internacionales de capital pueden considerarse como diferentes "industrias", como la inversión de cartera, la inversión extranjera directa y los préstamos, entre otras categorías. Utilizando datos del Fondo Monetario Internacional, Grubel (2002) calculó los índices GL de las cuentas financieras de la balanza de pagos de Alemania. 
Además, Grubel calculó el índice GL de la variable IED de varios países desarrollados y también de regiones. El autor también realizó un análisis de otras "industrias" de la balanza de pagos, como la inversión de cartera y los préstamos. El estudio concluyó que existe un importante comercio intraindustrial de activos entre los países desarrollados, especialmente en lo referido a la inversión de cartera.

Para el presente análisis, el índice GL definido anteriormente se adaptó con el fin de considerar los flujos de inversión, según la siguiente expresión:

$$
I G L_{I E D}=\frac{\left(I E D_{\text {sal }}+I E D_{\text {en }}\right)-\left|I E D_{\text {sal }}-I E D_{\text {en }}\right|}{\left(I E D_{\text {sal }}+I E D_{\text {en }}\right)} \text { en que } 0 \leq I G L_{I E D} \leq 1
$$

donde:

$I G L_{I E D}=$ indice de inversión directa "intraindustrial"

$I E D_{\text {sal }}=$ inversión extranjera directa saliente

$I E D_{\text {en }}=$ inversión extranjera directa entrante

El índice GL adaptado permite calcular las entradas y salidas de IED y comprender la dinámica de los flujos o los volúmenes de una economía determinada. El resultado de la ecuación (2) estará siempre en el intervalo [0, 1]. Cuando el flujo se da solo, o predominantemente, en una dirección, el resultado del cálculo será cercano a 0 . Por el contrario, cuanto más cerca estén los valores de entrada y salida de IED, más cerca estará el resultado de la ecuación de 1.

Sin embargo, el índice tiene una serie de limitaciones. Si los flujos de IED de un país son predominantemente entrantes o salientes, el índice será el mismo, cercano a 0 , independientemente de la dirección. Además, si un país tiene tanto entradas como salidas de valores similares en un año determinado, el índice se mantendrá cercano a 1. Al tratarse de un índice relativo, debe interpretarse con precaución. No obstante, la aplicación del índice GL puede ser útil en las comparaciones y el análisis de los flujos de IED, entre otras cuestiones.

La sugerencia de este cálculo, con aplicaciones, apareció en Grubel (2002), y otros estudios aplicaron posteriormente el índice GL a los flujos de IED y a otras variables. Por ejemplo, Obstfeld (2004) aplicó el índice a los flujos de activos internacionales, para evaluar posibles desequilibrios en el endeudamiento de algunos países. Sin embargo, este autor calificó el índice como un índice de comercio de activos en dos direcciones, en lugar de un índice de comercio de activos intraindustrial. Grubel (2002) reconoció que los economistas habían sugerido que el trabajo publicado como comercio intraindustrial de activos debía renombrarse comercio bidireccional de activos. Aunque la opinión de Obstfeld (2004) es más coherente desde el punto de vista teórico, el presente estudio mantiene la taxonomía de Grubel. Otros estudios que aplican el índice GL a los activos son Lane y Milesi-Ferretti (2007) y Obstfeld (2012).

\section{El índice Grubel-Lloyd aplicado a la Argentina, el Brasil, Chile y México}

Con los datos sobre los volúmenes de inversión extranjera entrante $\left(I E D_{e n}\right)$ y local en el extranjero (IED sal $)$ obtenidos de la UNCTAD, la ecuación (2) permitió calcular el índice GL de cuatro países latinoamericanos seleccionados (Argentina, Brasil, Chile y México). Estos países fueron los principales receptores de IED en América Latina durante el período analizado, lo que justifica su selección para el análisis. El 
análisis utiliza el mismo indicador para el grupo de países desarrollados como comparador, con el fin de reforzar el debate sobre el movimiento de esta forma de capital².

Como se muestra en el gráfico 4, el índice de los países desarrollados es relativamente estable en comparación con los de los países de la muestra analizados a continuación; su nivel también es bastante alto - una media de 0,87 en el período 1995-2016- cuando se evalúan las entradas y salidas de forma concurrente, características que no se encuentran en ninguno de los cuatro países evaluados.

\section{Gráfico 4}

Países desarrollados: inversión extranjera directa entrante y saliente e índice Grubel-Lloyd, 1995-2016

(En miles de millones de dólares)

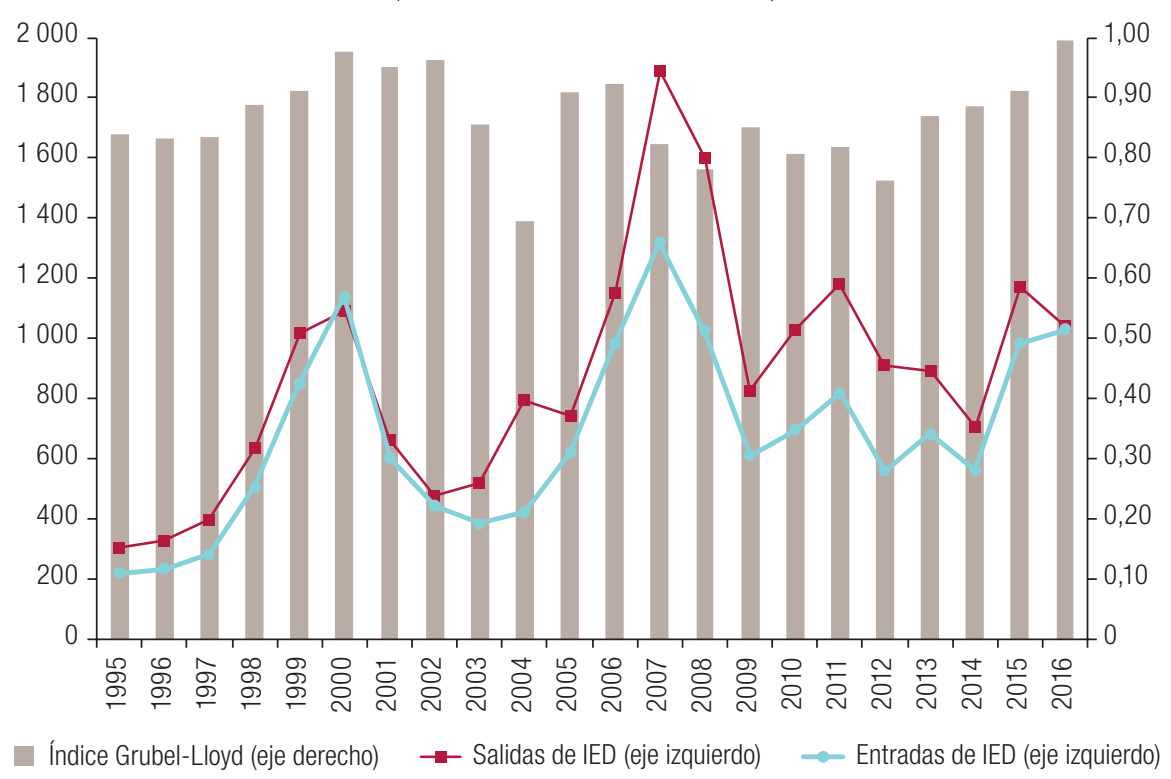

Fuente: Elaboración propia sobre la base de información de la Conferencia de las Naciones Unidas sobre Comercio y Desarrollo (UNCTAD).

También se ha calculado el índice GL de China, no solo por la importancia relativa de este país en los flujos mundiales, sino también porque pertenece al grupo de países en desarrollo, con el que se compararán los resultados obtenidos en los cuatro países analizados (Argentina, Brasil, Chile y México).

China muestra un comportamiento atípico en comparación con el resto de los países en desarrollo, ya sea por la cantidad de inversiones, tanto entrantes como salientes, que la convierten en el segundo y más importante exportador de IED, o por el comportamiento del índice GL calculado, cuya tendencia de crecimiento lleva a resultados con la escala máxima del indicador, es decir, cercanos a 1, ya que las entradas de dichos capitales han sido muy cercanas a las salidas, como se muestra en el gráfico 5.

\footnotetext{
2 Según la clasificación del Departamento de Asuntos Económicos y Sociales (DAES) de la Secretaría de las Naciones Unidas. Véanse más detalles en [en línea] http://www.un.org/en/development/desa/policy/wesp/wesp_current/2014wesp_country_ classification.pdf.
} 


\section{Gráfico 5}

China: inversión extranjera directa entrante y saliente e índice Grubel-Lloyd, 1995-2016

(En miles de millones de dólares)

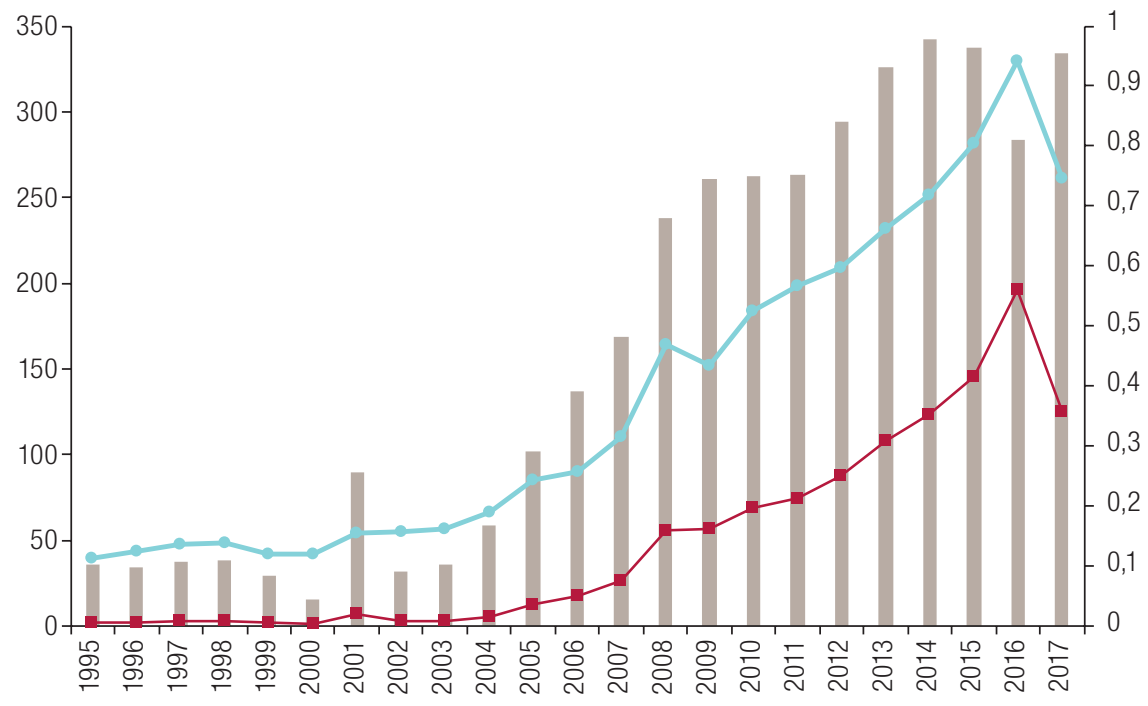

Índice Grubel-Lloyd (eje derecho) $\rightarrow$ Entradas de IED (eje izquierdo) $\rightarrow$ Salidas de IED (eje izquierdo)

Fuente: Elaboración propia sobre la base de información de la Conferencia de las Naciones Unidas sobre Comercio y Desarrollo (UNCTAD).

\section{Argentina}

La economía de la Argentina absorbió importantes entradas de IED en los años noventa como consecuencia de la relativa estabilidad económica proporcionada por el régimen de caja de conversión aplicado a principios de la década. A este respecto, el gráfico 6 muestra una tendencia al alza de las entradas de IED hasta 1999, tras lo cual se produjo una inflexión a raíz de la crisis monetaria del Brasil, que afectó a la economía argentina.

En el caso de las salidas, es decir, la inversión de los argentinos en el exterior, se observa un patrón de comportamiento similar en el período analizado, con una salida neta negativa en 2002, lo que significa que los residentes del país "desinvirtieron" los recursos que habían invertido en el exterior con anterioridad. La causa de este comportamiento puede atribuirse al colapso del régimen de caja de conversión, que condujo a un proceso de devaluación y a una mayor inestabilidad de la economía argentina.

Así, el índice GL fluctuó entre 1995 y 2016, manteniéndose por debajo de 0,3 en la mayor parte del período, lo que refleja la discrepancia entre las entradas y salidas de IED en el país.

Estos resultados se explican por el movimiento errático de las entradas y el pequeño volumen de salidas de IED. En general, los valores del índice GL son muy inferiores a los calculados en los casos del grupo de países desarrollados y de China. Esto indica un grado relativamente bajo de internacionalización de la producción durante el período analizado, a pesar de que la Argentina había logrado una amplia liberalización económica en la década de 1990.

Lo confirma la relación entre IED y PIB, que en la Argentina fue de apenas el 13\% en 2016, muy por debajo de los indicadores equivalentes del conjunto de América Latina $(40,5 \%)$ y de los demás países de la muestra, como se observa en el cuadro 3.

Como la proporción de salidas de IED es muy pequeña en los cuatro países de la muestra, no se hará la misma comparación con ninguno de ellos en este estudio. 


\section{Gráfico 6}

Argentina: inversión extranjera directa entrante y saliente e índice Grubel-Lloyd, 1995-2016

(En miles de millones de dólares)

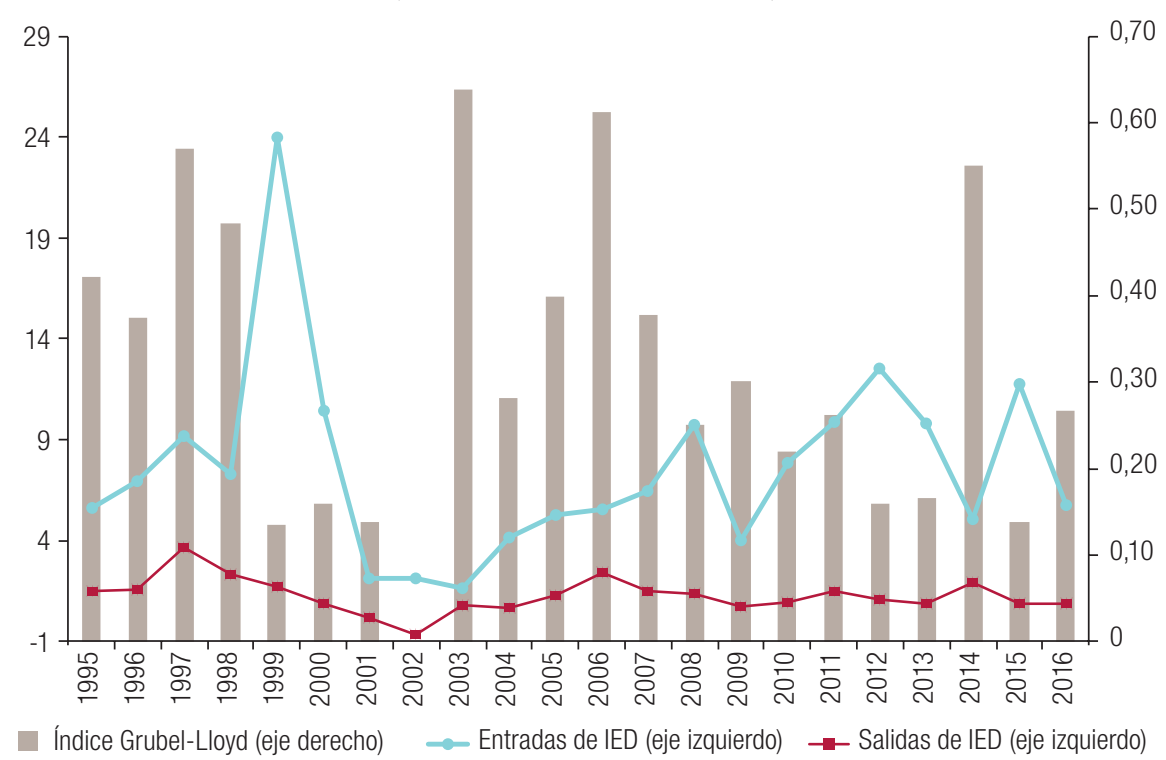

Fuente: Elaboración propia sobre la base de información de la Conferencia de las Naciones Unidas sobre Comercio y Desarrollo (UNCTAD).

\section{Brasil}

La economía brasileña recibió importantes entradas de IED en diferentes períodos de tiempo. El primer período (1997-2001) estuvo marcado por el proceso de privatización de las empresas estatales, mientras que el segundo (2003-2008) estuvo relacionado con el auge de los precios de las materias primas en los mercados internacionales y el crecimiento económico con estabilidad de precios que experimentó la economía brasileña. Tras la reducción de las entradas durante la crisis internacional de 2008, la trayectoria de crecimiento se reanudó en el período 2011-2016.

La inversión de los residentes brasileños en el extranjero $\left(I E D_{\text {sal }}\right)$ ha fluctuado, pero muestra una tendencia al alza desde 2003, interrumpida por la crisis de 2008. Como resultado, los flujos de IED produjeron un índice GL superior a 0,30 en solo tres años (2004, 2006 y 2008), lo que revela un patrón divergente de entradas y salidas de inversión en el período analizado.

El bajo nivel del índice, comparado con los del grupo de países desarrollados y China, se debe a la gran diferencia entre entradas y salidas. Brasil fue el séptimo mayor receptor de IED del mundo en el período, pero el trigésimo séptimo entre los "exportadores de IED". Además, los flujos de salida han experimentado una fuerte tendencia a la baja, como muestra el gráfico 7 . 


\section{Gráfico 7}

Brasil: inversión extranjera directa entrante y saliente e índice Grubel-Lloyd, 1995-2016

(En miles de millones de dólares)

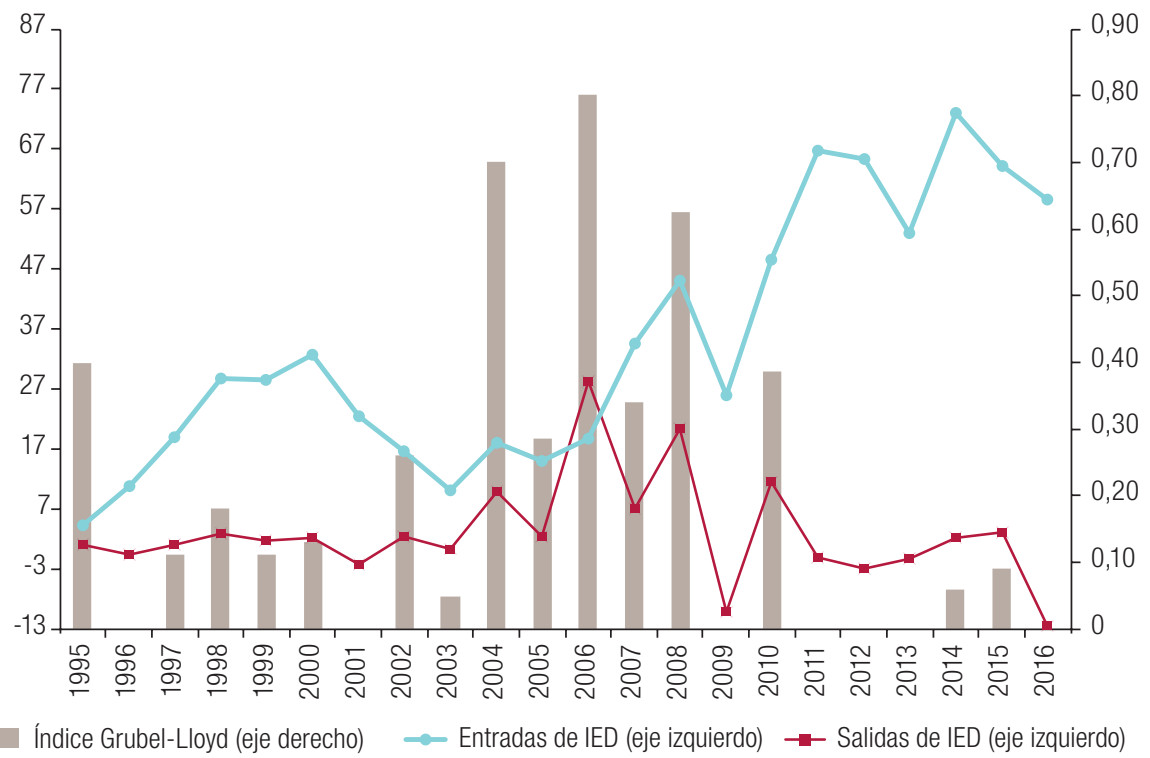

Fuente: Elaboración propia sobre la base de información de la Conferencia de las Naciones Unidas sobre Comercio y Desarrollo (UNCTAD)

\section{Chile}

La mayor parte de las entradas de IED en Chile se canaliza hacia el sector minero, lo que refleja la importancia del cobre para la economía del país. Las estadísticas oficiales muestran que alrededor del $35 \%$ del total de la inversión extranjera se encuentra en este segmento. Excluyendo los datos de los sectores no declarados, esto representa más del $50 \%$ del total de capital extranjero canalizado hacia los sectores productivos de Chile $^{3}$.

En el caso de las inversiones de residentes chilenos en el resto del mundo, la actividad minera vuelve a absorber la mayor parte del capital, ya que el 45\% del volumen de IED en 2016 estuvo vinculado a este sector. Los principales destinos de ese año fueron la Argentina, el Brasil, España y Luxemburgo.

En este sentido, el gráfico 8 muestra la mayor simetría entre las entradas y salidas de IED en la economía chilena. El resultado es una serie calculada en la que el índice GL es superior a 0,60 durante más de la mitad del período. Es decir, que Chile muestra un patrón relativamente más regular que los demás países cuando se comparan las entradas y salidas.

En el caso de las entradas y salidas de IED de Chile, tampoco se observa el comportamiento errático de los otros países de la muestra hasta 2012, cuando ambos flujos caen. Los flujos de salida también se han comportado de forma similar a los de entrada, lo que explica que su índice GL sea superior al calculado para la Argentina, el Brasil y México.

Asimismo, es posible argumentar que la apertura de Chile en la década de los setenta condujo a una importante internacionalización de su actividad productiva, de tal manera que su relación entre IED y PIB es del 101,1\%, por encima de los niveles informados tanto en el bloque de países desarrollados como en el latinoamericano, como se muestra en el cuadro 3.

3 Según estadísticas del Banco Central de Chile [en línea] https://si3.bcentral.cl/estadisticas/Principal1/Estudios/SE/BDP/ied.html. 


\section{Gráfico 8}

Chile: inversión extranjera directa entrante y saliente e índice Grubel-Lloyd, 1995-2016

(En miles de millones de dólares)

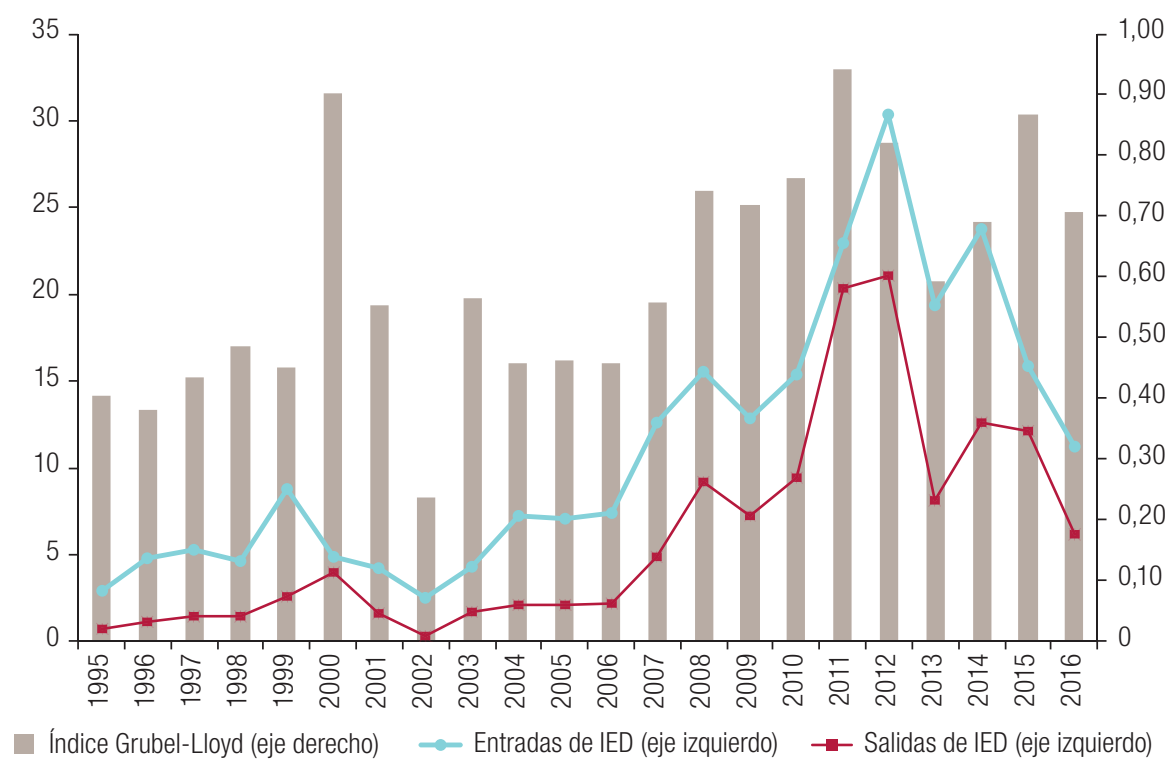

Fuente: Elaboración propia sobre la base de información de la Conferencia de las Naciones Unidas sobre Comercio y Desarrollo (UNCTAD).

\section{México}

El análisis de las entradas y salidas de inversión extranjera en la economía mexicana revela que el 50\% de los flujos acumulados de IED recibidos entre 2000 y 2016 procedieron de los Estados Unidos, y el 74,5\% se canalizó al sector industrial. Estos datos reflejan la conocida y fuerte relación económica de México con los Estados Unidos, en la que México sirve de eslabón en la cadena de producción manufacturera a través de sus instalaciones maquiladoras.

La entrada de inversiones extranjeras en la economía mexicana se tambaleó tras la crisis financiera internacional de 2007-2008. Con esta reducción y el aumento de los flujos de salida que comenzó en 2009, México comenzó a mostrar índices GL superiores a 0,50 (véase el gráfico 9). En cuanto al grado de internacionalización, desde el punto de vista de los flujos de entrada, México también tiene una importante participación de capital extranjero en su actividad económica. Su relación entre IED y PIB, del $44 \%$, es superior a la media latinoamericana (véase el cuadro 3). 


\section{Gráfico 9}

México: inversión extranjera directa entrante y saliente e índice Grubel-Lloyd, 1995-2016

(En miles de millones de dólares)

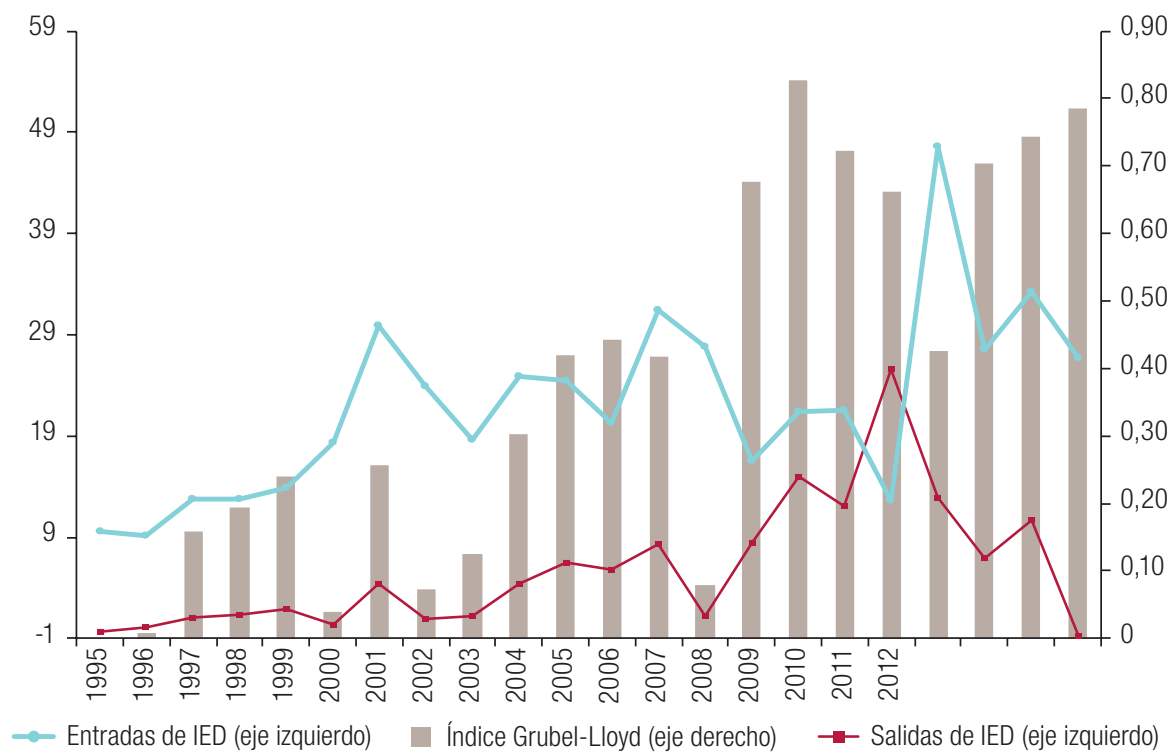

Fuente: Elaboración propia sobre la base de información de la Conferencia de las Naciones Unidas sobre Comercio y Desarrollo (UNCTAD).

Los resultados coinciden con el hallazgo de Grubel (2002), a saber, que los países emergentes tienden a tener un índice relativamente cercano a 0 hasta que se inicia un proceso de apertura comercial y financiera que no solo amplía las entradas, sino que también estimula una mayor salida. En la década de los noventa en particular, los países latinoamericanos, especialmente los cuatro países incluidos en el estudio, ampliaron el proceso de apertura comercial y financiera, lo que hizo que las entradas y salidas de IED se alinearan más, como se muestra en los gráficos.

Como resultado, el índice GL se acercó a 1, como se ha observado en las economías desarrolladas y también fue predicho por Grubel (2002). Obstfeld (2012) también llamó la atención sobre el mismo comportamiento, aunque el índice en este caso se aplicó a la posición bruta internacional de activos y pasivos de los países desarrollados y emergentes.

Sin embargo, la tendencia al alza del índice GL de los flujos de inversión de los países latinoamericanos observada en este estudio puede no estar consolidada, ya que, en la Argentina, el Brasil y México, el índice experimentó una caída al final del período analizado, debido a una reducción de las entradas o salidas de IED.

\section{Reflexiones finales}

El propósito de este artículo era analizar el comportamiento de las entradas y salidas de inversión extranjera en cuatro países latinoamericanos seleccionados (Argentina, Brasil, Chile y México) desde 1995 hasta 2016, mediante el índice de Grubel-Lloyd adaptado al comportamiento observado en los países desarrollados. Como se ha observado en el estudio, el índice de los países desarrollados se comporta de forma diferente al patrón identificado en los países de la muestra, ya que, en el primer grupo, el indicador, además de ser alto, es relativamente estable, lo que contrasta marcadamente con el comportamiento errático del índice en los casos de la Argentina, el Brasil, Chile y México. 
El análisis de las entradas y salidas de IED de estos países demuestra la importancia de esta variable para la economía de la región. Todas estas economías presentan una tendencia al alza en los flujos de IED, aunque con fluctuaciones debidas a una serie de acontecimientos, incluida la crisis económica mundial de 2008.

Sin embargo, de la información extraída de la aplicación del índice GL a estos países, se desprende que las entradas de IED han tendido a mostrar esta tendencia, pero también han divergido mucho de las salidas, especialmente en el caso de la Argentina.

En general, el índice GL permite realizar una evaluación comparativa entre los cuatro países y el bloque de países desarrollados, mostrando que, además de ser cuantitativamente inferior, el indicador no presenta el comportamiento estable típico de este grupo. Asimismo, en relación con China, cuyo índice GL ha aumentado significativamente en los últimos diez años, el grado de internacionalización de la producción de la Argentina, el Brasil y México es relativamente menor, mientras que Chile ya tiene un patrón más internacionalizado y efectivo. Así, como grupo de países en desarrollo, con diferentes perspectivas históricas y políticas que se reflejan en sus políticas económicas y procesos de participación en la economía internacional, es difícil entender el movimiento de la IED como tendencia regional sin un análisis de cada una de las economías que componen este grupo de países y las relaciones que establecen entre sí.

En lugar de invalidar el uso del índice GL como indicador de las tendencias de la economía internacional, estos resultados lo refuerzan, porque demuestran que es capaz de revelar aspectos de esta realidad que de otro modo no serían visibles. Así pues, al identificar el comportamiento de la IED en las distintas economías, ya sea como grupo o individualmente, se revelan las divergencias y las idiosincrasias. Otros estudios pueden aportar una explicación adicional de los resultados observados.

\section{Bibliografía}

Chesnais, F. (1996), A Mundialização do Capital, Río de Janeiro, Xamã.

Corazza, G. (2005), "A inserção do Brasil na Globalização Financeira”, documento presentado en el Congrès International Marx, París.

Dicken, P. (1998), Global Shift: Transforming the World Economy, Londres, Paul Chapman.

Grubel, H. (2002), "Intra-industry trade in assets", Frontiers of Research in Intra-Industry Trade, H. O. Lee y P. Lloyd (eds.), Nueva York, Palgrave Macmillan.

Grubel, H. y P. Lloyd (1975), Intra-Industry Trade: The Theory and Measurement of International Trade in Differentiated Products, Halsted Press.

Hay, C. y D. Marsh (2000), Demystifying Globalization, Palgrave, Basingstoke.

Kregel, J. A. (1996), "Riscos e implicações da globalização financeira para a autonomia de políticas nacionais", Economia e Sociedade, № 7.

Krugman, P. (1980), "Scale economies, product differentiation and the pattern of trade", American Economic Review, vol. 70.

(1979), "Increasing returns, monopolistic competition, and international trade", Journal of International Economics, vol. 9, № 4.

Lane, P. R. y G. M. Milesi-Ferretti (2007), "A global perspective on external positions", G7 Current Account Imbalances: Sustainability and Adjustment, R. Clarida, National Bureau of Economic Research (NBER), University of Chicago Press.

Martell, L. (2007), "The third wave in globalization theory", International Studies Review, № 9, vol. 2, Oxford. Michalet, C.A. (1985), Le Capitalisme Mondial, París, Presses Universitaries de France.

Nonnemberg, M. J. B. (2003), "Determinantes dos investimentos externos e impactos das empresas multinacionais no Brasil: as décadas de 1970 e 1990", Texto para discussão IPEA, № 969 [en línea] www.ipea.gov.br/pub/td/2003/td_0969.pdf. 
Obstfeld, M. (2012), "Financial flows, financial crises, and global imbalances", Journal of International Money and Finance, vol. 31, № 3.

(2004), "External adjustment", Review of World Economics, vol. 140, № 4.

Strange, S. (1979), "The management of surplus capacity: or how does theory stand up to protectionism 1970 s style?", International Organization, vol. 33, № 3.

UNCTAD (Conferencia de las Naciones Unidas sobre Comercio y Desarrollo) (2020), "Foreign direct investment: Inward and outward flows and stock, annual", UNCTAD Stat [en línea] https://unctadstat.unctad.org/ wds/TableViewer/tableView.aspx?Reportld=96740. 